\title{
Actively Marketed
}

National Cancer Institute

\section{Source}

National Cancer Institute. Actively Marketed. NCI Thesaurus. Code C101667.

Indicates that a product is currently being promoted for use. 